University of Windsor

Scholarship at UWindsor

$11-2013$

\title{
Nicholas Reactions in the Synthesis of Dicobalt Dibenzocyclooctyne Complexes
}

\author{
Sinisa Djurdjevic \\ University of Windsor \\ James R. Green \\ University of Windsor
}

Follow this and additional works at: https://scholar.uwindsor.ca/chemistrybiochemistrypub

Part of the Biochemistry, Biophysics, and Structural Biology Commons, and the Chemistry Commons

\section{Recommended Citation}

Djurdjevic, Sinisa and Green, James R.. (2013). Nicholas Reactions in the Synthesis of Dicobalt Dibenzocyclooctyne Complexes. Organic Letters, 15 (21), 5468-5471.

https://scholar.uwindsor.ca/chemistrybiochemistrypub/71

This Article is brought to you for free and open access by the Department of Chemistry and Biochemistry at Scholarship at UWindsor. It has been accepted for inclusion in Chemistry and Biochemistry Publications by an authorized administrator of Scholarship at UWindsor. For more information, please contact scholarship@uwindsor.ca. 


\title{
Nicholas Reactions in the Synthesis of Dicobalt Dibenzocyclooctyne Complexes
}

2013

Vol. 15, No. 21

$5468-5471$

\author{
Sinisa Djurdjevic and James R. Green* \\ Department of Chemistry and Biochemistry, University of Windsor, Windsor, ON, \\ Canada N9B $3 P 4$
}

jgreen@uwindsor.ca

Received September 10, 2013

ABSTRACT

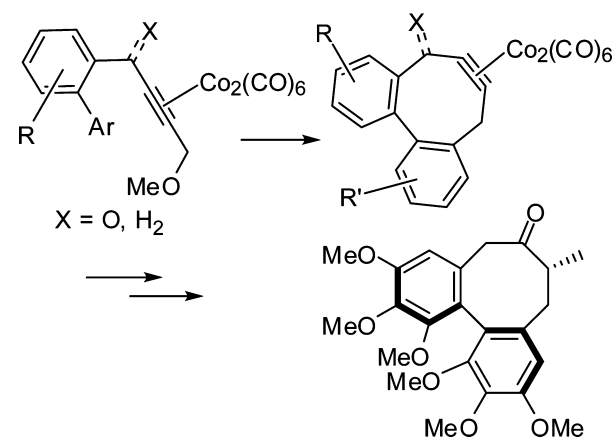

Hexacarbonyldicobalt complexes of biaryl-substituted 4-methoxybutynones and 4-methoxy-2-butynes undergo intramolecular Nicholas reactions to form dibenzocyclooctyne- $\mathrm{CO}_{2}(\mathrm{CO})_{6}$ complexes in good yields. Reductive decomplexation of the cyclization products is possible, and the method has been applied to a formal synthesis of isoschizandrin.

Cyclooctyne is well-known as the smallest of the simple cycloalkynes with sufficient stability to be capable of isolation in the conventional sense. ${ }^{1}$ This does not apply to all cyclooctyne derivatives, as increasing unsaturation in the eight-membered ring renders the compounds more marginally stable ${ }^{2}$ or incapable of isolation. ${ }^{3}$ In contrast, the hexacarbonyldicobalt complexes of cyclooctynes appear to have excellent stability. While direct preparation from cyclooctyne itself is known, ${ }^{4}$ this is synthetically limited. Several scattered reports of de novo construction of cyclooctyne- $-\mathrm{CO}_{2}(\mathrm{CO})_{6}$ complexes have been published,

(1) For reviews, see: (a) Krebs, A.; Wilke, J. Top. Curr. Chem. 1983, 109, 189. (b) Hopf, H.; Grunenberg, J. In Strained Hydrocarbons. Beyond the van't Hoff and Le Bel Hypothesis; Dodziuk, H., Ed.; WileyVCH: Weinheim, 2009; pp 375-397.

(2) (a) Varga, B. R.; Kallay, M.; Hegyi, K.; Beni, S.; Kele, P. Chem.Eur. J. 2012, 18, 822. (b) Krebs, A.; Oldenthal, J.; Kimling, H. Tetrahedron Lett. 1976, 4663. (c) Werner, C.; Hopf, H.; Grunenberg, J.; Jones, P. G. Eur. J. Org. Chem. 2010, 4027.

(3) (a) Meier, H.; Layer, A.; Zetzsche, A. Chem. Ztg. 1974, 98, 460. (b) Sletten, E. M.; Nakamura, H.; Jewett, J. C.; Bertozzi, C. R. J. Am. Chem. Soc. 2010, 132, 11799. (c) Gugel, H.; Meier, H. Chem. Ber. 1981, 113,1431 .

(4) (a) Bennett, M. A.; Donaldson, P. B. Inorg. Chem. 1978, 17, 1995. (b) Petersen, H.; Meier, H. Nouv. J. Chim. 1980, 4, 687.

(5) (a) Jamison, T. F.; Shambayati, S.; Crowe, W. E.; Schreiber, S. L. J. Am. Chem. Soc. 1994, 116, 5505. (b) Atkinson, R. C. J.; Hope-Weeks, L. J.; Mays, M. J.; Solan, G. A. J. Organomet. Chem. 2007, 692, 2076. including those resulting from Nicholas reaction chemistry, ${ }^{5}$ ring-closing metathesis, ${ }^{6}$ aldol and Michael reaction chemistry, ${ }^{7}$ Diels-Alder reactions,${ }^{8}$ and epoxide ring-openings. ${ }^{9}$ In addition, cyclic ether and amine complexes have been prepared. ${ }^{10}$ Despite the viability of systems of this class, there has been no attempt to prepare dibenzocyclooctynedicobalt complexes (1, Figure 1) or to explore their applicability toward dibenzocyclooctanecontaining compounds.

The dibenzocyclooctane lignans are a large group of natural products occurring widely, particularly in the Schizandraceae family. ${ }^{11}$ Their structural features and

(6) (a) Green, J. R. Synlett 2001, 353. (b) Young, D. G. J.; Burlison, J. A.; Peters, U. J. Org. Chem. 2003, 68, 3494.

(7) (a) Mitachi, K.; Shimizu, T.; Miyashita, M.; Tanino, K. Tetrahedron Lett. 2010, 51, 3983. (b) Inaba, K.; Takaya, J.; Iwasawa, N. Chem. Lett. 2007, 474.

(8) Iwasawa, N.; Inaba, K.; Nakayama, S.; Aoki, M. Angew. Chem., Int. Ed. 2005, 44, 7447.

(9) Nagumo, S.; Ishii, Y.; Sato, G.; Mizukami, M.; Imai, M.; Kawahara, N.; Akita, H. Tetrahedron Lett. 2009, 50, 26.

(10) (a) Isobe, M.; Hamajima, A. Nat. Prod. Rep. 2010, 27, 1204 and references therein. (b) Mizukami, M.; Saito, H.; Higuchi, T.; Imai, M.; Nadu, H.; Kawahara, N.; Nagumo, S. Tetrahedron Lett. 2007, 48, 7228. (c) Closser, K. D.; Quintal, M. M.; Shea, K. M. Org. Lett. 2009, 74, 3680. (d) Mukai, C.; Kojima, T.; Kawamura, T.; Inagaki, F. Tetrahedron 2013, 69,7659 . 


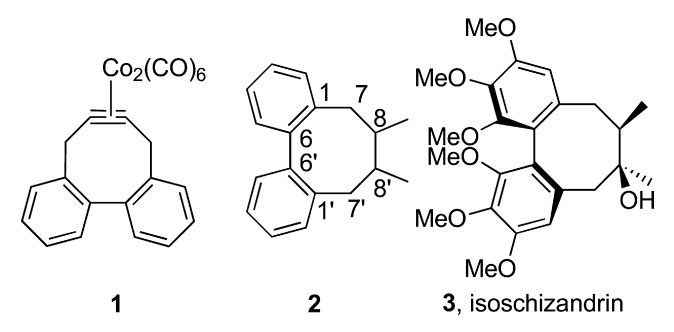

Figure 1. Dibenzocyclooctane lignan framework and $\mathbf{1 .}$

wide-ranging biological activities have made them recent attractive synthetic targets. Synthesis of the eightmembered rings of these systems is overwhelmingly accomplished either by aryl-aryl $\left(\mathrm{C} 6-\mathrm{C}^{\prime}\right)$ (see 2) coupling protocols ${ }^{11 \mathrm{a}, 12}$ or by assorted condensation or coupling reactions at the homobenzylic sites $\left(\mathrm{C} 8-\mathrm{C} 8^{\prime}\right)$ of functionalized 2,2'-diethylbiphenyls. Construction by way of benzylic-bishomobenzylic bond formation $\left(C 8^{\prime}-C 7^{\prime}\right)$ of biaryls is less common but known. ${ }^{13}$ Their preparation by way of $\mathrm{Cl}^{\prime}-\mathrm{C}^{\prime}$ coupling reactions, such as by electrophilic substitution protocols, is rare and on those occasions tend to be by dienone-phenol rearrangements. ${ }^{14,15}$

Our group has had recent success with the use of intramolecular Nicholas reaction chemistry in the preparation of dibenzocycloheptyne- $\mathrm{Co}_{2}(\mathrm{CO})_{6}$ complexes ${ }^{16}$ and have found the method useful in allocolchicine synthesis in conjunction with reductive decomplexation reactions. As a result of these developments, we have chosen to explore a Nicholas reaction approach to such dibenzocyclooctyne complexes, with a view toward their use in dibenzocyclooctane synthesis. Isoschizandrin (3), an antiulcer C-8 oxygenated dibenzocyclooctane lignan, was identified as a target compound relevant to this chemistry. ${ }^{17}$ Given the common occurrence of C7-oxygen substituted dibenzocyclooctane lignans in addition to their C8-hydroxy-substituted and nonoxygen-substituted counterparts, ${ }^{11 \mathrm{a}}$ we considered it of importance to include both $\gamma$-carbonyl cation $(\mathbf{4} \rightarrow \mathbf{5})$ and normal $(6 \rightarrow 7)$ versions of these Nicholas reactions.

(11) (a) Jiang, C.; Reiner, J.; Xie, J. Chem. Rev. 2005, 105, 4581. (b) See also: Bringmann, G.; Gulder, T.; Gulder, T. A. M.; Breuning, M. Chem. Rev. 2011, 111, 563. (c) Sefkow, M. Top. Curr. Chem. 2005, 243, 185.

(12) For a recent example, see: Zheng, S.; Aves, S. J.; Laraia, L.; Galloway, W. R. J. D.; Pike, K. G.; Wu, W.; Spring, D. R. Chem.-Eur. J. 2012, 18, 3193.

(13) (a) Li, Y.; Wang, Q.; Dong, L.; Guo, X.; Wang, W.; Xie, J.; Chang, J. Synthesis 2009, 3383. (b) Monovich, L. G.; Huerou, Y. L.; Rönn, M.; Molander, G. A. J. Am. Chem. Soc. 2000, 122, 52. (c) Robin, J.-P.; Dhal, R.; Brown, E. Tetrahedron 1984, 40, 3509.

(14) (a) Bowden, B. F.; Read, R. W.; Taylor, W. C. Aust. J. Chem. 1981, 34, 799. (b) Pelter, A.; Ward, R. S.; Abd-El-Ghani, A. J. Chem. Soc, Perkin Trans. 1 1992, 2249.

(15) For a rare, low-yielding, exception, see: Plummer, E. L.; Seiders, R. A. H.; Seelye, D. E; Stewart, R. R. Pestic. Sci. 1984, 15, 509.

(16) (a) Djurdjevic, S.; Yang, F.; Green, J. R. J. Org. Chem. 2010, 75, 8241. (b) Djurdjevic, S.; Green, J. R. Org. Lett. 2007, 9, 5505.

(17) (a) Warshawsky, A. M.; Meyers, A. I. J. Am. Chem. Soc. 1990, 112, 8090. (b) Tanaka, M.; Mukaiyama, C.; Mitsuhashi, H.; Maruno, M.; Wakamatsu, T. J. Org. Chem. 1995, 60, 4339. (c) Molander, G. A.; George, K. M.; Monovich, L. G. J. Org. Chem. 2003, 68, 9533. (d) Isolation: Ikeya, Y.; Taguchi, H.; Mitsuhashi, H.; Takeda, S.; Kase, Y.; Aburada, M. Phytochemistry 1988, 27, 569.
Table 1. Preparation of 4
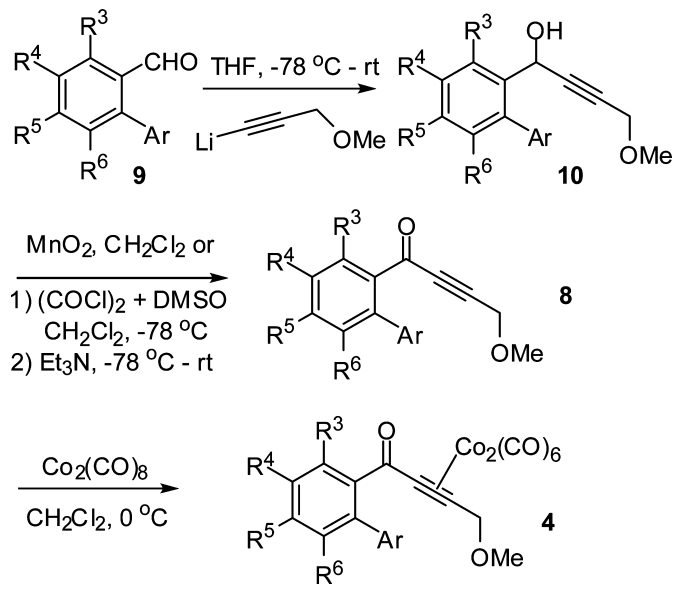

\begin{tabular}{cccc}
\hline $\mathbf{9}$ & $\mathbf{1 0}$ & $\mathbf{8}$ & $\mathbf{4}$ \\
\hline $\mathbf{9 a}, \mathrm{R}^{4}=\mathrm{OMe}, \mathrm{Ar}=$ & $\mathbf{1 0 a}(86 \%)$ & $\mathbf{8 a}(96 \%)^{a}$ & $\mathbf{4 a}(93 \%)$ \\
$2,3,4-(\mathrm{MeO})_{3} \mathrm{C}_{6} \mathrm{H}_{2}$ & & & \\
$\mathbf{9 b}, \mathrm{R}^{3}=\mathrm{R}^{4}=\mathrm{OMe}, \mathrm{Ar}=$ & $\mathbf{1 0 b}(97 \%)$ & $\mathbf{8 b}(78 \%)^{b}$ & $\mathbf{4 b}(90 \%)$ \\
$2,3,4-(\mathrm{MeO})_{3} \mathrm{C}_{6} \mathrm{H}_{2}$ & & & \\
$\mathbf{9 c}, \mathrm{R}^{4}=\mathrm{OMe}, \mathrm{Ar}=3-$ thienyl & $\mathbf{1 0 c}(94 \%)$ & $\mathbf{8 c}(79 \%)^{b}$ & $\mathbf{4 c}(87 \%)$ \\
$\mathbf{9 d}, \mathrm{R}^{4}=\mathrm{R}^{5}=\mathrm{R}^{6}=\mathrm{OMe}, \mathrm{Ar}=$ & $\mathbf{1 0 d}(98 \%)$ & $\mathbf{8 d}(92 \%)^{a}$ & $\mathbf{4 d}(93 \%)$ \\
$2,3,4-(\mathrm{MeO})_{3} \mathrm{C}_{6} \mathrm{H}_{2}$ & & & \\
${ }^{a} \mathrm{MnO}_{2}, \mathrm{CH}_{2} \mathrm{Cl}_{2}, \mathrm{rt}^{b}$ Swern conditions. & & \\
\end{tabular}

The precursors for $\gamma$-carbonyl cation complexes were selected to be 4-alkoxy-2-butynoyl-substituted biaryls (8) (Table 1), which were prepared from the biarylcarboxaldehydes $(9)^{16}$ in straightforward fashion.

Reaction of the aldehydes with the lithium acetylide derived from 3-methoxy-1-propyne (propargyl methyl ether) gave the benzylic/propargylic alcohols (10) in good to excellent yield (Table 1); subsequent oxidation with $\mathrm{MnO}_{2}$, or using Swern conditions when $\mathrm{MnO}_{2}$ performed sluggishly, gave the corresponding ketones (8). Complexation of the alkyne functions of these alkynones with $\mathrm{Co}_{2}(\mathrm{CO})_{8}$ then afforded 4 readily.

The biaryls bearing 4-methoxy-2-butynyl functions (11) were also prepared from the biarylcarboxaldehydes (9) in three steps (Table 2). Reduction of the aldehyde function to the benzylic alcohols (12) occurred cleanly and in excellent yields. Substitution of bromide for the alcohol function (13) was accomplished with $\mathrm{PBr}_{3}$. For tetramethoxy-substituted 13f, reaction of the benzyl bromide with the lithium acetylide derived from propargyl methyl ether afforded 11f in acceptable yield. In other cases, this protocol gave poor yields; conversely, use of this lithium acetylide in the presence of $\mathrm{InCl}_{3}$ and catalytic amounts of $\mathrm{Pd}(\mathrm{dppf}) \mathrm{Cl}_{2}$ gave 11c-e successfully. ${ }^{18}$ Once again, the alkyne functions underwent complexation by $\mathrm{Co}_{2}(\mathrm{CO})_{8}$ to afford 6 readily.

Cyclization reactions of the aryl alkynone complexes were investigated first. While previous experience has

(18) Pérez, I.; Sestelo, J. P.; Sarandeses, L. A. J. Am. Chem. Soc. 2001, 123,4155 . 
Table 2. Preparation of 6
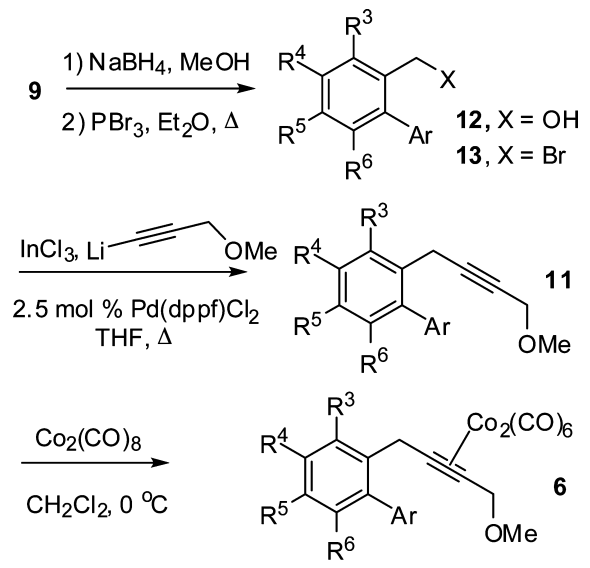

\begin{tabular}{ccccc}
\hline $\mathbf{9}$ & $\mathbf{1 2}$ & $\mathbf{1 3}$ & $\mathbf{1 1}$ & $\mathbf{6}$ \\
\hline $\mathbf{9 c}, \mathrm{R}^{4}=\mathrm{OMe}, \mathrm{Ar}=3$-thienyl & $\mathbf{1 2 c}(89 \%)$ & $\mathbf{1 3 c}(73 \%)$ & $\mathbf{1 1 c}(61 \%)$ & $\mathbf{6 c}(86 \%)$ \\
$\mathbf{9 d}, \mathrm{R}^{4}=\mathrm{R}^{5}=\mathrm{R}^{6}=\mathrm{OMe}$, & $\mathbf{1 2 d}(93 \%)$ & $\mathbf{1 3 d}(99 \%)$ & $\mathbf{1 1 d}(69 \%)$ & $\mathbf{6 d}(99 \%)$ \\
$\mathrm{Ar}=2,3,4-(\mathrm{MeO})_{3} \mathrm{C}_{6} \mathrm{H}_{2}$ & & & & \\
$\mathbf{9 e}, \mathrm{R}^{4}=\mathrm{OMe}, \mathrm{Ar}=$ & $\mathbf{1 2 e}(92 \%)$ & $\mathbf{1 3 e}(63 \%)$ & $\mathbf{1 1 e}(66 \%)$ & $\mathbf{6 e}(86 \%)$ \\
$3,5-\mathrm{Me}_{2} \mathrm{C}_{6} \mathrm{H}_{3}$ & & & & \\
$\mathbf{9 f}, \mathrm{R}^{4}=\mathrm{OMe}_{3} \mathrm{Ar}=$ & $\mathbf{1 2 f}(99 \%)$ & $\mathbf{1 3 f}(80 \%)$ & $\mathbf{1 1 f}(61 \%)^{a}$ & $\mathbf{6 f}(78 \%)$ \\
$3,4,5-(\mathrm{MeO})_{3} \mathrm{C}_{6} \mathrm{H}_{2}$ & & & &
\end{tabular}

${ }^{a} \mathrm{InCl}_{3}$ and $\mathrm{Pd}(\mathrm{dppf}) \mathrm{Cl}_{2}$ omitted.

shown that Nicholas reaction based $\gamma$-carbonyl cations are more reliably generated using $\mathrm{Bu}_{2} \mathrm{BOTf}$ as Lewis acid, ${ }^{19}$ $\mathrm{BF}_{3} \cdot \mathrm{OEt}_{2}\left(3\right.$ equiv, $0^{\circ} \mathrm{C}$ ) gave good rates of reaction in the case of 4 (Table 3 ). Reactions were conducted at $4 \times 10^{-3}$ $\mathrm{M}$; doubling the concentration reduced yield modestly (entry 4 versus entry 5). The addition of $i$ - $\operatorname{Pr}_{2} \mathrm{NEt}$ (1.5 equiv, with 4 equiv $\mathrm{BF}_{3} \cdot \mathrm{OEt}_{2}$ ) occasionally resulted in lesser amounts of decomposition due to presumed scavenging of liberated acid and consequently gave greater yields. Ultimately, tetramethoxy $\mathbf{4 a}$ afforded $\mathbf{5 a}$ in $85 \%$ yield, whereas hexamethoxy substrate $4 \mathbf{d}$ gave $\mathbf{5 d}$ in $81 \%$ yield. In the case of pentamethoxy substrate $\mathbf{4 b}$ and thiophenecontaining $\mathbf{4 c}$, the reactions were conducted in the presence of $i$ - $\operatorname{Pr}_{2} \mathrm{NEt}$; the former afforded $\mathbf{5 b}$ in $71 \%$ yield, whereas the latter gave $5 \mathbf{c}$ in in $68 \%$ yield, as a $14: 1$ mixture of products reacting at $\mathrm{C}-2$ and $\mathrm{C}-4\left(\mathbf{5} \mathbf{c}^{\prime}\right)$ of the thiophene ring.

Cyclization reactions involving the benzyl alkyne complexes 6 succeeded under similar conditions. In none of the cases was the presence of additional $i$ - $\operatorname{Pr}_{2} \mathrm{NEt}$ necessary, and the reactions were somewhat more rapid than for 4 . We attributed this to the lack of a competitively Lewis basic and electron-withdrawing carbonyl in 6. In the event, hexamethoxy-substituted $\mathbf{6 d}$ gave dibenzocyclooctyne 7d in $93 \%$ yield in $1 \mathrm{~h}$, whereas tetramethoxy-substituted 6f afforded $7 \mathbf{f}$ in $91 \%$ yield over the same period. The substrates with less electron rich arene nucleophiles also underwent cyclization rapidly, as thiophene-substituted 6c afforded 7c in 77\% yield over $2 \mathrm{~h}$, while dimethylsubstituted 6 e gave $7 \mathrm{e}$ in $88 \%$ over $2 \mathrm{~h}$. In the $6 \mathbf{c} \rightarrow 7 \mathrm{c}$ case,

(19) Jacobi, P. A.; Buddhu, S. C.; Fry, D.; Rajeswari, S. J. Org. Chem. 1997, 62, 2894.
Table 3. Intramolecular Nicholas Reactions
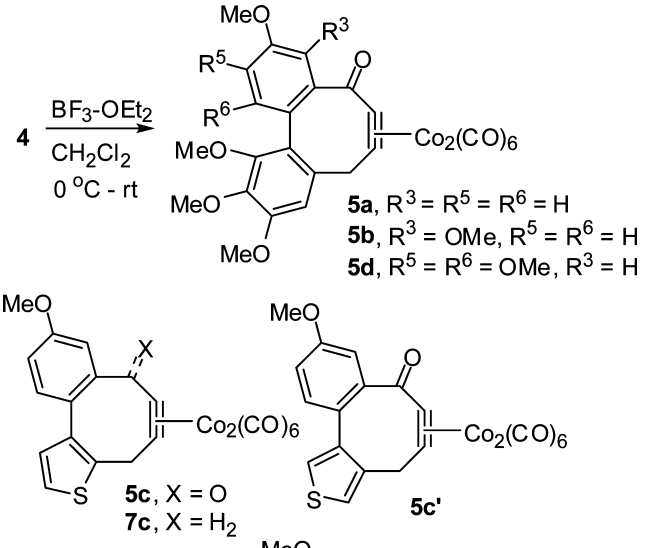

$\mathrm{MeO}$ $\mathbf{b}, \mathrm{R}^{5}=\mathrm{R}^{6}=\mathrm{OMe}, \mathrm{R}^{3}=\mathrm{H}$

6

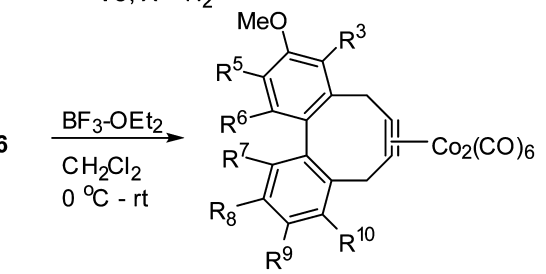

7d, $\mathrm{R}^{3}=\mathrm{R}^{10}=\mathrm{H}, \mathrm{R}^{5}=\mathrm{R}^{6}=\mathrm{R}^{7}=\mathrm{R}^{8}=\mathrm{R}^{9}=\mathrm{OMe}$ 7e, $R^{3}=R^{5}=R^{6}=R^{7}=R^{9}=H, R^{8}=R^{10}=M e$ $7 f, R^{3}=R^{5}=R^{6}=R^{7}=H, R^{8}=R^{9}=R^{10}=O M e$

entry starting material conditions ${ }^{a}$ time (h) product yield (\%)

$\begin{array}{rllllr}1 & \mathbf{4 a} & \text { A } & 5 & \mathbf{5 a} & 85 \\ 2 & \mathbf{4 b} & \mathrm{B} & 6 & \mathbf{5 b} & 71 \\ 3 & \mathbf{4 c} & \mathrm{B} & 8 & \mathbf{5 c} & 68^{b} \\ 4 & \mathbf{4 d} & \mathrm{A} & 8 & \mathbf{5 d} & 81 \\ 5 & \mathbf{4 d} & \mathrm{A}^{c} & 8 & \mathbf{5 d} & 71 \\ 6 & \mathbf{6 c} & \mathrm{A} & 1 & \mathbf{7 c} & 77 \\ 7 & \mathbf{6 d} & \mathrm{A} & 2 & \mathbf{7 d} & 93 \\ 8 & \mathbf{6 e} & \mathrm{A} & 2 & \mathbf{7 e} & 88 \\ 9 & \mathbf{6 f} & \mathrm{A} & 1 & \mathbf{7 f} & 91\end{array}$

${ }^{a} \mathrm{~A}: \mathrm{BF}_{3} \cdot \mathrm{OEt}_{2}$ (3 equiv), $0{ }^{\circ} \mathrm{C}$ to $\mathrm{rt}, \mathrm{CH}_{2} \mathrm{Cl}_{2}\left(4 \times 10^{-3} \mathrm{M}\right) ; \mathrm{B}$ : $\mathrm{BF}_{3} \cdot \mathrm{OEt}_{2}$ (4 equiv), ${ }^{\mathrm{i}} \mathrm{Pr}_{2} \mathrm{NEt}$ (1.5 equiv) $0{ }^{\circ} \mathrm{C}$ to rt, $\mathrm{CH}_{2} \mathrm{Cl}_{2}\left(4 \times 10^{-3} \mathrm{M}\right)$. ${ }^{b} \mathbf{5 c}: 5 \mathbf{c}^{\prime}=14: 1 .{ }^{c} 8 \times 10^{-3} \mathrm{M}$.

there was no evidence of $\mathrm{C}-4$ reactivity on the thiophene ring competing with the $\mathrm{C}-2$ substitution.

Decomplexation reactions of the cyclooctynones were studied using 5d as a model compound (Scheme 1). Use of $\mathrm{Bu}_{3} \mathrm{SnH}^{20}$ resulted in the successful removal of the $\mathrm{Co}_{2}(\mathrm{CO})_{6}$ unit with predominant overreduction of the alkyne function to give cyclooctanone 14 (82\% yield), along with a small amount of cyclooctenone $\mathbf{1 5}$ (9\% yield). The cyclooctenone $\mathbf{1 5}$ could be obtained as the predominant product $(44 \%$ yield, $51 \%$ based on recovered starting material) by employing 2 equiv of $\mathrm{NaH}_{2} \mathrm{PO}_{2}$ in 2-methoxyethanol; ${ }^{21}$ this was accompanied by $13 \%$ of cyclooctanone 14 and 14\% of unreacted 5d. The use of the conventionally employed 5 equiv of hypophosphite gave greater amounts of cyclooctanone 14 (29\%), at the expense of $15(36 \%)^{22}$

(20) Hosokawa, S.; Isobe, M. Tetrahedron Lett. 1998, 39, 2609.

(21) Takai, S.; Ploypradith, P.; Hamajima, A.; Kira, K.; Isobe, M. Synlett 2002, 588 . 
Scheme 1. Reductive Decomplexations

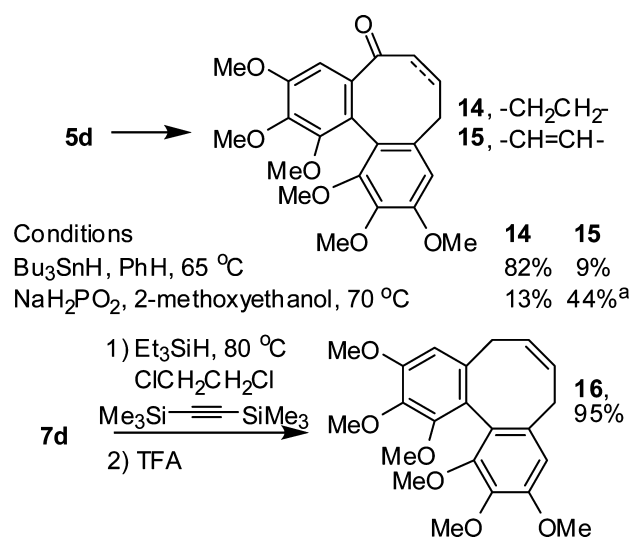

${ }^{a} 51 \%$ based on recovered starting material.

In the case of dibenzocyclooctyne complex $\mathbf{7 d}$, the reductive decomplexation was much more straightforward. Employing our hydrosilylation-protodesilylation modification of the Isobe protocol, ${ }^{16,23} \mathbf{7 d}$ afforded $\mathbf{1 6}$ cleanly ( $95 \%$ yield).

Alkene $\mathbf{1 6}$ is well suited for use in the synthesis of isoschizandrin. Epoxidation of the alkene function occurred readily with dimethyldioxirane (DMDO), giving 17 in $87 \%$ yield (Scheme 2). Lewis acid mediated cuprate attack of the epoxide gave alcohol $\mathbf{1 8}$ with complete diastereoselectivity $(92 \%$ yield). Swern oxidation of the alcohol then afforded 19 in $95 \%$ yield. The Meyers group has previously converted enantioenriched 19 into (-)-isoschizandrin (79\% yield, along with $9 \%$

(22) Use of $\mathrm{Et}_{3} \mathrm{SiH}$ resulted in a regioisomeric mixture of vinylsilanebearing cyclooctenones which resisted protodesilylation.

(23) Kira, K.; Tanda, H.; Hamajima, A.; Baba, T.; Takai, S.; Isobe, M. Tetrahedron 2002, 58,6485 .
Scheme 2. Completion of Isoschizandrin Formal Synthesis
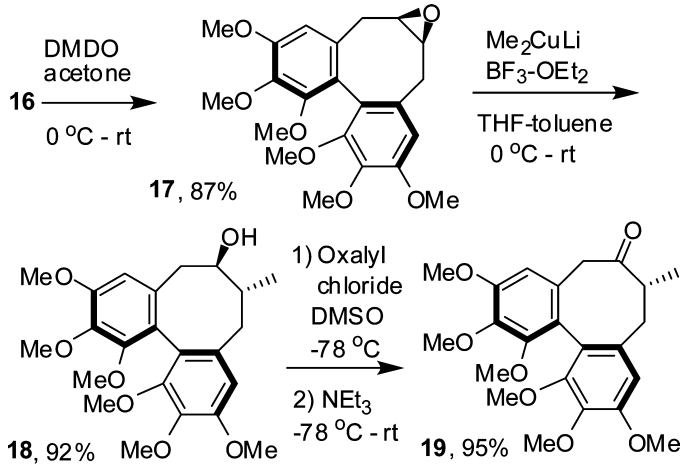

(-)-schizandrin) by methyllithium addition; ${ }^{17 a}$ consequently, this constitutes a formal synthesis of racemic isoschizandrin.

In summary, we have found that intramolecular Nicholas reactions of both biaryl-4-methoxybutynonedicobalt complexes and biaryl-4-methoxy-2-butynedicobalt complexes afford the corresponding dibenzocyclooctyne- $-\mathrm{Co}_{2}(\mathrm{CO})_{6}$ complexes in good yields. Reductive decomplexation of these cyclization products is possible, and the process may be applied to the formal synthesis of isoschizandin.

Acknowledgment. We are grateful to NSERC (Canada), the Canada Foundation for Innovation, and Ontario Innovation Trust for support of this research.

Supporting Information Available. Experimental procedures and spectroscopic data for all new compounds. This material is available free of charge via the Internet at http://pubs.acs.org.

The authors declare no competing financial interest. 